AperTO - Archivio Istituzionale Open Access dell'Università di Torino

\title{
Upcoming biological therapies in systemic lupus erythematosus.
}

\section{This is the author's manuscript}

Original Citation:

Availability:

This version is available http://hdl.handle.net/2318/1521981

since 2016-11-25T11:42:00Z

Published version:

DOI:10.1016/j.intimp.2015.04.049

Terms of use:

Open Access

Anyone can freely access the full text of works made available as "Open Access". Works made available under a Creative Commons license can be used according to the terms and conditions of said license. Use of all other works requires consent of the right holder (author or publisher) if not exempted from copyright protection by the applicable law. 
This Accepted Author Manuscript (AAM) is copyrighted and published by Elsevier. It is posted here by agreement between Elsevier and the University of Turin. Changes resulting from the publishing process - such as editing, corrections, structural formatting, and other quality control mechanisms - may not be reflected in this version of the text. The definitive version of the text was subsequently published in INTERNATIONAL

IMMUNOPHARMACOLOGY, 27 (2), 2015, 10.1016/j.intimp.2015.04.049.

You may download, copy and otherwise use the AAM for non-commercial purposes provided that your license is limited by the following restrictions:

(1) You may use this AAM for non-commercial purposes only under the terms of the CC-BY-NC-ND license.

(2) The integrity of the work and identification of the author, copyright owner, and publisher must be preserved in any copy.

(3) You must attribute this AAM in the following format: Creative Commons BY-NC-ND license (http://creativecommons.org/licenses/by-nc-nd/4.0/deed.en), 10.1016/j.intimp.2015.04.049

The publisher's version is available at:

http://linkinghub.elsevier.com/retrieve/pii/S1567576915002131

When citing, please refer to the published version.

Link to this full text:

http://hdl.handle.net/2318/1521981 


\section{Upcoming Biological therapies in Systemic lupus erythematosus}

Savino Sciascia ${ }^{1,2}$, Eva Talavera-Garcia ${ }^{3}$, Dario Roccatello ${ }^{1}$, Simone Baldovino ${ }^{1}$, Elisa Mengatti ${ }^{4}$, Maria Jose' Cuadrado ${ }^{2}$

1 Centro di Ricerche di Immunologia Clinica ed Immunopatologia e Documentazione su Malattie Rare (CMID), Department of Clinical and Biological Sciences, Università di Torino, Italy

2 Louise Coote Lupus Unit, Guy's and St Thomas' NHS Foundation Trust, St Thomas' Hospital, London, UK

3. Internal medicine department, Universitary Hospital "Reina Sofia", Cordoba, Spain.

4. Experimental Medicine and Clinical Pathology Unit, Department of Clinical and Biological Sciences, Università di Torino, Italy

Correspondence:

Dr Maria Jose' Cuadrado. Louise Coote Lupus Unit, Guy's and St Thomas' NHS Foundation Trust, St Thomas' Hospital, St Thomas' Hospital, London SE1 7EH. Tel: +44 02071883568. Fax: +44 02076202658. Mail: mjcuadrado@yahoo.com 


\section{Abstract:}

Systemic lupus erythematosus (SLE) is a chronic autoimmune condition with unpredictable course, intermingled with flares and periods of remission. Although the prognosis of the disease has improved in the past decades, current therapies are still associated with treatment-related complications. Recently, there has been major progress in the understanding of the pathogenesis of SLE, paving the way for the development of new biological agents, potentially revolutionising the treatment of SLE.

This review summarizes available data on novel biological therapies for SLE, focusing on recent results from clinical trials.

As a result of treatment strategies based upon individualized therapeutic approach, it is hoped that the clinical view of SLE will change from a severe autoimmune disease to a condition in which significant damage, mortality and treatment related complications can be prevented in the majority of SLE patients.

Keywords

Systemic lupus erythematosus, biological agents, rituximab, belimumab 


\section{Introduction:}

Systemic lupus erythematosus (SLE) is an autoimmune condition heterogeneous from clinical and immunological point of view, with variable and unpredictable course, intermingled with periods of flares and remission. For decades, the therapy for SLE has been based on glucorticosteroids, hydroxychloroquine, and the immunosuppressive agents[1]. These approaches have been related to a remarkable improvement in the prognosis of SLE. However, the occurrence of refractory disease and adverse effects related to conventional therapies such as glucocorticoids and the cytotoxic agents sill represent a challenge for physician, requiring the development of more efficacious treatments with higher safety profile in SLE. Rituximab and, more recently, belimumab are the most extensively used biological agents in SLE.

Although the results of two randomized controlled trials suggest that the use of Rituximab in SLE may be controversial, it is still extensively used 'off label', especially in refractory cases to standard treatment. Belimumab has been the first biological agent approved by the Food and Drug agency (FDA) for the treatment of active SLE in addition to standard of care $[1,2]$. Despite the initial enthusiasm related to the approval of a tailored approach for SLE treatment, there are still uncertainties on the selection of the ideal patient that might benefit from this agent and the optimal duration of therapy $[3,4]$.

In the last years, an increasing number of new biological therapies have being tested in SLE with heterogeneous results.

The current goal of development of novel biological agents for SLE is to identify therapies that are potentially more effective than conventional approaches and at the same time are able to reduce the risk of organ damage and therapy-induced side effects. This review summarizes available data on novel upcoming biological therapies for SLE, beyond rituximab and belimumab, focusing on recent results from clinical trials (Table 1). 


\section{B-cell targeted therapies}

B cells can be selectively targeted for depletion either via direct B cell surface molecules CD19 and CD20 (Rituximab, Ocrelizumab) and CD22 (Epratuzumab) or by inhibition of B cell survival factors BLyS (Belimumab) and APRIL (Atacicept) [3].

It is out of the scope of this review to explore the clinical efficacy of Rituximab in SLE since this has been extensively discussed elsewhere [5]. However, due this topic is worthy some considerations.

The use of rituximab in patients with SLE has been investigated in two randomised controlled trials, EXPLORER (The Exploratory Phase II/III SLE Evaluation of Rituximab)[6] and LUNAR (Lupus Nephritis Assessment With Rituximab)[7] with negative results regarding superiority to conventional treatment. However, before concluding that Rituximab is not effective in SLE, a critical evaluation of the design of the EXPLORER and LUNAR trials is required. Firstly, a high percentage of patients included were likely to have had mild to moderate SLE (especially in the EXPLORER trial) with no history of poor response to conventional therapies. This fact, in itself, may potentially justify why Rituximab was not superior to the other therapies in this setting. Secondly, considering concomitant therapies, very high doses of corticosteroids were permitted in both arms of these trials, leading to significant differences not being evident in a short-term follow-up. Thirdly, some authors have speculated a possible synergistic effect of Rituximab in combination with immunosuppressive agents (cyclophosphamide or mycophenolate)[8] but this aspect was not evaluated in these RCTs. Fourthly, LUNAR and EXPLORE included different sub sets of patients (mainly North and Central-South American patients) when compared to the majority of patients from uncontrolled studies (European). This observation about ethnicity might be considered as a variable therapeutic response to the different immunosuppressive agents [9]. 
Finally, and most importantly, aiming to prove the superiority of Rituximab over current first-line therapies in SLE (corticosteroids, cyclophosphamide, and mycophenolate) does not reflect the use of Rituximab in clinical practice, where rituximab is mainly considered in refractory cases to these therapies.

\section{Ocrelizumab}

Ocrelizumab is a humanized anti-CD20 monoclonal antibody. When compared to rituximab, ocrelizumab may have a safer profile in term of immunogenicity and complement activation, theoretically leading to a reduced frequency of adverse infusion reactions and the development of drug neutralizing antibodies.

BEGIN and renal BELONG are two phase III RCTs investigating the efficacy of ocrelizumab in non-renal and renal SLE respectively [10]. Ocrelizumab was given at different doses (400 or $1000 \mathrm{mg}$ intravenously) on day 1 and day 15. A repeat single dosing was administered every 4 months. The BEGIN study was interrupted early when the decision was made that ocrelizumab was not likely to benefit patients with active SLE. In the BELONG a total of 381 patients were recruited to investigate the efficacy of ocrelizumab in patients with proliferative lupus nephritis (class III/IV) on top of high-dose glucocorticoids and either MMF or CYC (according to the Euro-lupus protocol). The trial was terminated early because of the higher rate of serious infections in patients receiving ocrelizumab compared to placebo (mainly in those receiving ocrelizumab and MMF). However, in patients who had passed the 32-week treatment point (223/381), the overall renal response in the ocrelizumab arm was (67\%) was not significantly higher than that of placebo (67\% Vs. 55\%) [11].

\section{Anti-CD22}

\section{Epratuzumab}


Epratuzumab is a humanised monoclonal antibody targeting the CD22 surface receptor on mature $B$ cells [12].

Two randomized placebo-controlled trials (ALLIVIATE 1 and ALLIVIATE 2, 14 and 90 recruited patients, respectively) investigating the use of epratuzumab in addition to standard of care in SLE patients with moderate to severe activity reported a clinical improvement compared to placebo [13]. Epratuzumab was well tolerated without severe adverse events. However, these studies were terminated because of the disruption of drug supply [14].

Subsequently, ENBLEM, a more recent Phase Ilb RCT (trial not powered for significance) in 227 SLE patients with moderate to severe disease activity (excluding severe neuropsychiatric and renal disease showed that the proportion of responders was higher in all epratuzumab groups than with placebo. A post hoc analyses showed that a cumulative dose of $2400 \mathrm{mg}$ of epratuzumab was associated with a significantly better clinical improvement. The frequencies of AEs and SAEs, including infusion reactions, were not different across all groups of patients [15].

These promising results have lead to two phase III RCTs (EMBODY 1 and 2), aiming to investigate the clinical efficacy of Epratuzumab in the treatment of patients with moderate to severe SLE, in addition to conventional treatment [12].

\section{B Lymphocyte Stimulator (BLyS) and A Proliferation Inducing Ligand (APRIL) targeted therapy}

\section{Belimumab}

Belimumab is an fully humanized IgG1 monoclonal antibody that specifically binds to soluble trimeric BLyS and inhibiting its activity [16]. The clinical efficacy and safety of this 
new agent have been tested in two RTC, BLISS-52 [2] and BLISS-76 [17]. Together, the two trials included 1684 lupus patients with mild to moderate disease activity (excluding renal or CNS involvment). In the BLISS-52 study [2], a beneficial effects of belimumab were noted using the SLE responder index (SRI) with the belimumab $10 \mathrm{mg} / \mathrm{kg}$, with the difference being apparent at week 16. In the BLISS-76 study, the belimumab $10 \mathrm{mg} / \mathrm{kg}$ group also met the primary efficacy end point at week 52 (SRI rate 43.2 vs $33.5 \%$ in placebo; $p=0.02$ ) [17]. Both RTCs demonstrated a significant improvement in disease outcome with $10 \mathrm{mg} / \mathrm{kg}$ of Belimumab when compared to placebo in terms of the cumulative risk of disease flares and time to first flare $[17,18]$.

Post hoc analyses of the two BLISS RTCs demonstrated that patients with SELENASLEDAI > 10, low complement, anti-dsDNA positivity or corticosteroid use at baseline had greater benefit from belimumab (measured at week 52 by SRI) when compare to placebo and to those without these characteristics [19]. Secondary end points such as severe disease flares, corticosteroid sparing effect, improvement in fatigue, and health-related quality of life also showed greater effects in the low complement/anti-dsDNA positive subgroup of belimumab-treated patients. Patients with renal, neurologic, or vasculitic involvement, elevated anti-dsDNA or BLyS levels, or low C3 at baseline had increased risk of disease flare over 1 year

Results from BLISS-52 and BLISS-76 supported the use of Belimumab in the treatment of SLE and in 2011 Belimumab was approved by the FDA and EMA and has become the first drug approved for SLE for over 50 years [19].

The results remain positive with a maintained reduction in corticosteroid use and low rates of adverse effects in a seven-year follow up of lupus patients treated with belimumab [20]. A $70 \%$-decline from baseline in autoantibodies to dsDNA at 7 years after treatment was also observed.

Taken the above together, these results suggest that targeting BLyS with the novel 
biologic Belimumab can provide significant clinical benefit to SLE patients and is well tolerated long-term. However, few considerations are necessary. Belimumab has not been invesigated and is not indicated in patients with severe active neuropsychiatric lupus and lupus nephritis (proteinuria > $6 \mathrm{~g} / \mathrm{day}$; serum creatinine $\ddagger 2.5 \mathrm{mg} / \mathrm{dl}$; recent hemodialysis). Indeed, less than $6 \%$ of SLE patients in BLISS-52 and BLISS-72 had proteinuria of $>2$ g/day. A post hoc analysis on 267 (16\%) SLE patients with renal disease showed that numerically more patients treated with belimumab had improvement in proteinuria and renal remission when compared to placebo, especially to receiving MMF or with serological activity [21]. However, interpretation of the results should be taken with cautions due to the small number of patients. A new study of belimumab in lupus nephritis is in progress (BLISS-LN) (NCT01639339)

\section{Tabalumab and Blisibimod}

Owing the recent FDA and EMEA approval for belimumab, two further anti-BLyS agents are currently being assessed in a phase III RCT to evaluate their benefit in the treatment of SLE[22, 23].

Blisibimod (A-623) is a fusion protein between the Fc portion of $\lg G$ and four BAFF-binding domains peptide that selectively binds to BLyS. It is a subcutaneous potent BAFF inhibitor agent. High dose Blisibimod (200mg once weekly) produced significantly higher responder rates (measured as $\geq 7$ or $\geq 8$ point reduction in SLEDAI) when compared to placebo in a phase II trial (PEARL-SC). Moreover, a subset of severe to moderate lupus patients showed an even greater improvement with $41.7 \%$ responder rate achieving either $\geq 7$ or $\geq 8$ SLEDAI point decrease in the high dose blisibimod group compared to placebo $(p=0.002$, $p<0.001$ respectively). Similarly, normalization of biomarker of SLE activity (decrease in anti-ds DNA $(p<0.001)$ and increase in C3 $(p<0.01)$ and C4 $(p<0.001))$ was observed 
in the blisibimod group [24]. The drug was well tolerated at all doses with no increase in the incidence of infections and SAEs. A Phase III clinical trial is in progress (CHABLISSC1-NCT01395745).

Tabalumab (LY2127399) is a fully humanized monoclonal antibody directed against both soluble and membrane bound BLyS. Clinical efficacy of tabalumab in patients with active rheumatoid arthritis (RA) with an inadequate response to methotrexate but naive to biological therapy was assed in a phase II randomized controlled trial. Despite the promising early results in RA, it has been announced that further development of Tabalumab in SLE would be discontinued due to insufficient efficacy [25] in two phase III RCTs (ILLUMINATE 1 and ILLUMINATE 2) [25, 26]. In brief, in the ILLUMINATE 1 study, Tabalumab did not achieve the primary endpoint (significant improvement on SLE Responder Index-5), at either dose studied. In ILLUMINATE 2, the higher dose of Tabalumab met this endpoint. However, collectively, the data from ILLUMINATE 1 and 2 did not meet the producer's expectations for efficacy in the context of existing treatments. It is worth mentioning the overall safety profile showed a similar frequency of adverse events in patients treated with either Tabalumab or conventional treatment.

\section{Atacicept}

Atacicept is a recombinant fusion protein consisting in the TACI receptor that binds both BLyS and APRIL fused with the Fc portion of IgG. In a phase I RCT 49 mild to moderate SLE patients treated with Atacicept showed an attenuation in mature B cells and dose dependent decreases in autoantibody levels, when compared to placebo [27]. However, despite the early positive expectations, a phase I/II RCT of Atacicept in patients with lupus nephritis was prematurely terminated due to safety concerns [28]. 


\section{$\underline{\text { T cell targeted therapies }}$}

\section{Edratide}

Edratide is a tolerogenic peptide based on the sequence of the first complementaritydetermining (CDR1) region of a anti-DNA monoclonal antibody (16/6 idiotype). Preliminary studies in humans confirmed data from animal models showing that edratide downregulates pathogenic cytokines and apoptosis, IFN-a gene expression, and upregulates immunosuppressive molecules and Tregs cells in peripheral blood [29-31]. However, a 24-week Phase II study of 340 SLE patients failed to achieve the primary end point of a reduction in SLEDAI-2K scores was and was prematurely interrupted [32].

\section{Rigerimod (Lupuzor)}

Rigerimod is peptide that binds MHC class II. Although its mechanism of action remains not fully understood, preliminary data showed that rigerimod blocks inappropriate T-cell reactivity to MHC-presented self-peptides, resulting in restoring immune tolerance [33, 34]. Twenty patients with active SLE were treated with 2-weekly subcutaneous injection of rigerimod $(200 \mu \mathrm{g})$ in an early Phase lla study. Rigerimod was well tolerated and an improvement of disease activity and a reduction in anti-dsDNA titers were observed [35]. Similar results were obtained in a subsequent Phase Ilb randomized placebo-controlled trial involving 136 SLE patients, showing a a significantly higher SRI than placebo at week 12 (62 vs 39\%) [36]. Further studies are currently ongoing.

\section{Laquinimod}

Laquinimod has been originally investigated in the treatment of relapsing-remitting multiple sclerosis [37]. Laquinimod downregulates the pro-inflammatory cytokines (IL-6, IL-12, IL17, IL-23, and TNF-a) but increases the production of IL-10, exerting an immunomodulating effects on antigen presenting cells that direct $\mathrm{T}$ cells. 
Preliminary results from a Phase Ila randomized placebo-controlled study including 46 patients with active lupus nephritis showed that association of laquinimod $(0.5 \mathrm{mg}$ and 1.0 $\mathrm{mg} /$ day) to MMF and corticosteroid had an additive effect in improving renal function and proteinuria [38]. No increase in side effect was seen, paving the way for further investigation.

\section{$\underline{\text { Toleragen molecule }}$}

\section{Abetimus sodium (LJP394)}

Abetimus sodium is an intravenously administered tetrameric oligonucleotide conjugate that tolerizes B-cells by cross-linking antidouble-stranded DNA antibodies receptors on their cell surfaces and triggering the signal transduction pathways inducing B-cell to anergy or apoptosis. Given the importance of anti-dsDNA antibodies in the pathogenesis of lupus nephritis, the Phase II and III trials were designed to evaluate whether treatment with abetimus sodium could prolong the time to renal flare in cohorts of patients at high risk of nephritic flares [39-41]. A preliminary placebo-controlled study showed a significant and persistent reduction of anti-dsDNA titers in lupus patients receiving the highest dose of abetimus. This observation was not associated with an increase risk of adverse events [41]. Following these positive results, a_multicenter Phase II/III trial including 230 patients with lupus nephritis showed a significantly reduction in the number of renal flares and prolonged the time to renal flare at 76 weeks compared to placebo in a subset of patients with high-affinity serum IgG fraction for the DNA epitope of abetimus [42]. Nevertheless, these results were not confirmed in two subsequent Phase III trials including 317 and 943 (ASPEN trail) SLE patients respectively. Abetimus (either at the dose of $100 \mathrm{mg} /$ week or $900 \mathrm{mg} /$ week) did not reach the studies' outcome in terms of prolonging the time to renal flare, the need for rescue immunosuppressive therapy, or the time to major SLE flares as compared to placebo $[43,44]$. 


\section{$\underline{\text { Targeting proteasomes }}$}

In 2001, Fröhlich and co-workers [45] reported the first case of the successful use of twiceweekly bortezomib, a proteasome inhibitor in a patient with SLE and concomitant multiple myeloma, proving clinical support to the preliminary evidence of the efficacy of bortezomib in mouse models of lupus.

However, the high incidence of neurological, gastrointestinal, and hematological side effects related to bortezomib still represent the major limiting factor for further studies with this drug in SLE.

Recently, different scheme (once-weekly regimen) have been proposed suggesting the possible usefulness of the of bortezomib therapy in SLE. This regimen has already been introduced in $\mathrm{MM}$ trials, leading to a decrease in haematological, gastrointestinal and neurological side effects, accompanied by a similar efficacy. Further studies are eagerly needed.

\section{Cytokine blockade targeted therapies}

Tocilizumab (anti-IL-6 receptor $\mathrm{mAb}$ )

Tocilizumab is a humanised monoclonal antibody direct to IL-6 receptor. An open-label Phase I [46] study of tocilizumab in 16 SLE patients with mild to moderate showed an improvement in the SLEDAI score by $>4$ points in more than half of the patients, as well as a reduction in anti-dsDNA levels. Indeed, arthritis improved in all patients suffering from this manifestation at baseline.

However, it is worth noting that the infection rate was as high as $69 \%$ of patients. Further studies are warranted. 
Sirukumab (anti-IL-6 mAb)

Sirukumab is also a humanised monoclonal antibody that binds to IL-6 and inhibits its biological activity. A Phase I placebo-controlled study in 46 patients with systemic or cutaneous lupus [47] showed a dose-independent reduction in total while cell, absolute neutrophil and platelet counts and minor elevation in total cholesterol levels. More recently, a phase II trial with sirukumab in lupus patients with lupus nephritis failed to prove an improvement in proteinuria. Moreover, infection rate was higher than expected, leading to the interruption of the trial.

Sifalimumab (anti-interferon alpha (IFN- $\alpha)$ )

Sifalimumab is a human IgG1 monoclonal antibody targeting IFN- $\alpha[48,49]$. A recent phase Ilb trial showed that SLE patients treated with sifalimumab met the study primary endpoint by the SLE Responder Index (SRI-4) at Day 365. Clinical benefits in organspecific outcomes measures (joints, skin) was also observed [50]. Interestingly, a improvement in fatigue was also noticed.

\section{Rontalizumab,}

Rontalizumab is A human IgG1 monoclonal antibody targeting all known isoforms of human IFN-a. A Phase I trial of rontalizumab in 60 SLE patients demonstrated its safety and efficacy in reducing IFN signature[51]. A following a phase II study in 159 SLE patients with moderate severe non renal SLE showed overall similar response rates (evaluated by $\mathrm{SRI}$ and BILAG or SRI) between the treatment and placebo groups at week 24. However, when analysed in a post hoc analysis, Rontalizumab treatment was associated with improvement in signs and symptoms of SLE, flare rates and steroid burden at week 24 in a defined group with low signature gene expression as Metric (ISM)[52]. 


\section{Discussion:}

Encouraging preliminary results of ongoing studies such as those using epratuzumab and blisibimod, and the recent approval of belimumab further support the concept that targeting B-cell remains a promising approach in the treatment of SLE. Upcoming synthetic peptides and new oral immunomodulator agent may also prove to be effective treatments for SLE. However, one should bare in mind that the huge heterogeneity of clinical response among SLE patients may reflect the clinical variability of the disease Whether these novel modalities are synergistic to conventional drugs, the optimal dosages, and duration of treatment have to be explored. Assessment tools have to be standardized and efficacy end points have to be appropriately defined. Post-marketing surveillance and registry data are also essential to evaluate the long-term safety, efficacy, and cost-effectiveness of these novel therapies. 



\section{References}

1 Chan VS, Tsang HH, Tam RC, Lu L, Lau CS. B-cell-targeted therapies in systemic lupus erythematosus. Cellular \& molecular immunology. 2013; 10: 133-42. 10.1038/cmi.2012.64.

2 Navarra SV, Guzman RM, Gallacher AE, Hall S, Levy RA, Jimenez RE, Li EK, Thomas M, Kim HY, Leon MG, Tanasescu C, Nasonov E, Lan JL, Pineda L, Zhong ZJ, Freimuth W, Petri MA. Efficacy and safety of belimumab in patients with active systemic lupus erythematosus: a randomised, placebo-controlled, phase 3 trial. Lancet. 2011; 377 : 721-31. 10.1016/S0140-6736(10)61354-2.

3 Ramos-Casals M, Sanz I, Bosch X, Stone JH, Khamashta MA. B-cell-depleting therapy in systemic lupus erythematosus. The American journal of medicine. 2012; 125: 327-36. 10.1016/j.amjmed.2011.09.010.

4 Jordan N, D'Cruz DP. Belimumab for the treatment of systemic lupus erythematosus. Expert review of clinical immunology. 2015; 11: 195-204. 10.1586/1744666X.2015.996550.

5 Ramos-Casals M, Soto MJ, Cuadrado MJ, Khamashta MA. Rituximab in systemic lupus erythematosus: A systematic review of off-label use in 188 cases. Lupus. 2009; 18 : 767-76. 10.1177/0961203309106174.

6 Merrill JT, Neuwelt CM, Wallace DJ, Shanahan JC, Latinis KM, Oates JC, Utset TO, Gordon C, Isenberg DA, Hsieh HJ, Zhang D, Brunetta PG. Efficacy and safety of rituximab in moderately-to-severely active systemic lupus erythematosus: the randomized, doubleblind, phase II/III systemic lupus erythematosus evaluation of rituximab trial. Arthritis and rheumatism. 2010; 62: 222-33. 10.1002/art.27233.

7 Rovin BH, Furie R, Latinis K, Looney RJ, Fervenza FC, Sanchez-Guerrero J, Maciuca R, Zhang D, Garg JP, Brunetta P, Appel G. Efficacy and safety of rituximab in 
patients with active proliferative lupus nephritis: the Lupus Nephritis Assessment with Rituximab study. Arthritis and rheumatism. 2012; 64: 1215-26. 10.1002/art.34359.

8 Lu TY, Jonsdottir T, van Vollenhoven RF, Isenberg DA. Prolonged B-cell depletion following rituximab therapy in systemic lupus erythematosus: a report of two cases. Annals of the rheumatic diseases. 2008; 67: 1493-4. 10.1136/ard.2008.091124.

9 Rivera TL, Belmont HM, Malani S, Latorre M, Benton L, Weisstuch J, Barisoni L, Tseng CE, Izmirly PM, Buyon JP, Askanase AD. Current therapies for lupus nephritis in an ethnically heterogeneous cohort. The Journal of rheumatology. 2009; 36: 298-305. 10.3899/jrheum.080335.

10 Reddy V, Jayne D, Close D, Isenberg D. B-cell depletion in SLE: clinical and trial experience with rituximab and ocrelizumab and implications for study design. Arthritis research \& therapy. 2013; 15 Suppl 1: S2. 10.1186/ar3910.

11 Mysler EF, Spindler AJ, Guzman R, Bijl M, Jayne D, Furie RA, Houssiau FA, Drappa J, Close D, Maciuca R, Rao K, Shahdad S, Brunetta P. Efficacy and safety of ocrelizumab in active proliferative lupus nephritis: results from a randomized, double-blind, phase III study. Arthritis and rheumatism. 2013; 65: 2368-79. 10.1002/art.38037.

12 Wallace DJ, Goldenberg DM. Epratuzumab for systemic lupus erythematosus. Lupus. 2013; 22: 400-5. 10.1177/0961203312469692.

13 Wallace DJ, Gordon C, Strand V, Hobbs K, Petri M, Kalunian K, Houssiau F, Tak PP, Isenberg DA, Kelley L, Kilgallen B, Barry AN, Wegener WA, Goldenberg DM. Efficacy and safety of epratuzumab in patients with moderate/severe flaring systemic lupus erythematosus: results from two randomized, double-blind, placebo-controlled, multicentre studies (ALLEVIATE) and follow-up. Rheumatology (Oxford). 2013; 52: 1313-22. 10.1093/rheumatology/ket129.

14 UCB. announces start of phase III programme with epratuzumab for patients with moderate to severe systemic lupus erythematosus. [Press release]. [Accessed on 
19/09/2014]. Available from: . http://wwwucbpresscentrecom/News/UCB-announces-startof-phase-III-programme-with-epratuzumab-for-patients-with-moderate-to-severe-sys1a4aspx 2010.

15 Wallace DJ, Kalunian K, Petri MA, Strand V, Houssiau FA, Pike M, Kilgallen B, Bongardt S, Barry A, Kelley L, Gordon C. Efficacy and safety of epratuzumab in patients with moderate/severe active systemic lupus erythematosus: results from EMBLEM, a phase $\mathrm{llb}$, randomised, double-blind, placebo-controlled, multicentre study. Annals of the rheumatic diseases. 2014; 73: 183-90. 10.1136/annrheumdis-2012-202760.

16 Cancro MP, D'Cruz DP, Khamashta MA. The role of B lymphocyte stimulator (BLyS) in systemic lupus erythematosus. The Journal of clinical investigation. 2009; 119: 1066-73. $10.1172 / \mathrm{JCl} 38010$.

17 Furie R, Petri M, Zamani O, Cervera R, Wallace DJ, Tegzova D, Sanchez-Guerrero J, Schwarting A, Merrill JT, Chatham WW, Stohl W, Ginzler EM, Hough DR, Zhong ZJ, Freimuth W, van Vollenhoven RF. A phase III, randomized, placebo-controlled study of belimumab, a monoclonal antibody that inhibits B lymphocyte stimulator, in patients with systemic lupus erythematosus. Arthritis and rheumatism. 2011; 63: 3918-30. 10.1002/art.30613.

18 Merrill JT, Ginzler EM, Wallace DJ, McKay JD, Lisse JR, Aranow C, Wellborne FR, Burnette M, Condemi J, Zhong ZJ, Pineda L, Klein J, Freimuth WW. Long-term safety profile of belimumab plus standard therapy in patients with systemic lupus erythematosus. Arthritis and rheumatism. 2012; 64: 3364-73. 10.1002/art.34564.

19 Hahn BH. Belimumab for systemic lupus erythematosus. The New England journal of medicine. 2013; 368: 1528-35. 10.1056/NEJMct1207259.

20 Ginzler EM, Wallace DJ, Merrill JT, Furie RA, Stohl W, Chatham WW, Weinstein A, McKay JD, McCune WJ, Zhong ZJ, Freimuth WW, Petri MA. Disease control and safety of 
belimumab plus standard therapy over 7 years in patients with systemic lupus erythematosus. The Journal of rheumatology. 2014; 41: 300-9. 10.3899/jrheum.121368.

21 Dooley MA, Houssiau F, Aranow C, D'Cruz DP, Askanase A, Roth DA, Zhong ZJ, Cooper S, Freimuth WW, Ginzler EM. Effect of belimumab treatment on renal outcomes: results from the phase 3 belimumab clinical trials in patients with SLE. Lupus. 2013; 22: 63-72. 10.1177/0961203312465781.

22 ClinicalTrials.gov [Internet]. Bethesda (MD): National Library of Medicine (US). 29th Feb 2000. Identifier NCT01395745, A Randomised, Double-Blind, Placebo-Controlled Phase 3 Study to Evaluate the Efficacy and Safety of Blisibimod Administration in Subjects with Systemic Lupus Erythematosus (CHABLIS-SC1); 14th July 2011 - [cited 8th April 2014]; [about 6 screens]. Available from: http://clinicaltrials.gov/ct2/show/NCT01395745

23 ClinicalTrials.gov [Internet]. Bethesda (MD): National Library of Medicine (US). 29th Feb 2000. Identifier NCT01196091, A Phase 3, Multicenter, Randomized, Double Blind, Placebo- controlled Study to Evaluate the Efficacy and Safety of Subcutaneous LY2127399 in Patients with Systemic Lupus Erythematosus (SLE); 3rd September 2010 [cited 8th April 2014]; [about 6 screens]. Available from: http://clinicaltrials.gov/ct2/show/NCT01196091

24 Stohl W. Biologic differences between various inhibitors of the BLyS/BAFF pathway: should we expect differences between belimumab and other inhibitors in development? Current rheumatology reports. 2012; 14: 303-9. 10.1007/s11926-012-0254-6.

25 Eli Lilly, (2014). Lilly to Discontinue Development of Tabalumab Based on Efficacy Results in Phase 3 Lupus Studies. [online] Available at: https://investor.lilly.com/releasedetail.cfm?ReleaselD=874281 [Accessed 17 Nov. 2014]. 26 Zhang J, Roschke V, Baker KP, Wang Z, Alarcon GS, Fessler BJ, Bastian H, Kimberly RP, Zhou T. Cutting edge: a role for B lymphocyte stimulator in systemic lupus erythematosus. J Immunol. 2001; 166: 6-10. 
27 Dall'Era M, Chakravarty E, Wallace D, Genovese M, Weisman M, Kavanaugh A, Kalunian K, Dhar P, Vincent E, Pena-Rossi C, Wofsy D. Reduced B lymphocyte and immunoglobulin levels after atacicept treatment in patients with systemic lupus erythematosus: results of a multicenter, phase $\mathrm{lb}$, double-blind, placebo-controlled, doseescalating trial. Arthritis and rheumatism. 2007; 56: 4142-50. 10.1002/art.23047.

28 Ginzler EM, Wax S, Rajeswaran A, Copt S, Hillson J, Ramos E, Singer NG. Atacicept in combination with MMF and corticosteroids in lupus nephritis: results of a prematurely terminated trial. Arthritis research \& therapy. 2012; 14: R33. 10.1186/ar3738.

29 Sharabi A, Azulai H, Sthoeger ZM, Mozes E. Clinical amelioration of murine lupus by a peptide based on the complementarity determining region-1 of an autoantibody and by cyclophosphamide: similarities and differences in the mechanisms of action.

Immunology. 2007; 121: 248-57. 10.1111/j.1365-2567.2007.02565.x.

30 Sthoeger ZM, Sharabi A, Dayan M, Zinger H, Asher I, Sela U, Mozes E. The tolerogenic peptide hCDR1 downregulates pathogenic cytokines and apoptosis and upregulates immunosuppressive molecules and regulatory $\mathrm{T}$ cells in peripheral blood mononuclear cells of lupus patients. Human immunology. 2009; 70: 139-45.

31 Sthoeger Z, Zinger H, Sharabi A, Asher I, Mozes E. The tolerogenic peptide, hCDR1, down-regulates the expression of interferon-alpha in murine and human systemic lupus erythematosus. PloS one. 2013; 8: e60394. 10.1371/journal.pone.0060394.

32 Urowitz M ID, Wallace DJ, PRELUDE Study Group. Prelude --edratide phase II study outcome -- from predefined analyses to more recent assessment approaches [abstract]. Annals of the rheumatic diseases. 2011: 315.

33 Monneaux F, Lozano JM, Patarroyo ME, Briand JP, Muller S. T cell recognition and therapeutic effect of a phosphorylated synthetic peptide of the $70 \mathrm{~K}$ snRNP protein administered in MR/Ipr mice. European journal of immunology. 2003; 33: 287-96. 10.1002/immu.200310002. 
34 Monneaux F, Parietti V, Briand JP, Muller S. Importance of spliceosomal RNP1 motif for intermolecular T-B cell spreading and tolerance restoration in lupus. Arthritis research \& therapy. 2007; 9: R111. 10.1186/ar2317.

35 Muller S, Monneaux F, Schall N, Rashkov RK, Oparanov BA, Wiesel P, Geiger JM, Zimmer R. Spliceosomal peptide P140 for immunotherapy of systemic lupus erythematosus: results of an early phase II clinical trial. Arthritis and rheumatism. 2008; 58: 3873-83. 10.1002/art.24027.

36 Zimmer R, Scherbarth HR, Rillo OL, Gomez-Reino JJ, Muller S. Lupuzor/P140 peptide in patients with systemic lupus erythematosus: a randomised, double-blind, placebo-controlled phase Illb clinical trial. Annals of the rheumatic diseases. 2013; 72 : 1830-5. 10.1136/annrheumdis-2012-202460.

37 Bruck W, Zamvil SS. Laquinimod, a once-daily oral drug in development for the treatment of relapsing-remitting multiple sclerosis. Expert review of clinical pharmacology. 2012; 5: 245-56. 10.1586/ecp.12.12.

38 Jayne D AG, Chan TM, et al. A randomized controlled study of laquinimod in active lupus nephritis patients in combination with standard of care. 2013: 164.

39 Mosca M, Baldini C, Bombardieri S. LJP-394 (abetimus sodium) in the treatment of systemic lupus erythematosus. Expert opinion on pharmacotherapy. 2007; 8: 873-9. 10.1517/14656566.8.6.873.

40 Strand V, Aranow C, Cardiel MH, Alarcon-Segovia D, Furie R, Sherrer Y, Tumlin J, Wallace DJ, Crawford B. Improvement in health-related quality of life in systemic lupus erythematosus patients enrolled in a randomized clinical trial comparing LJP 394 treatment with placebo. Lupus. 2003; 12: 677-86.

41 Furie RA, Cash JM, Cronin ME, Katz RS, Weisman MH, Aranow C, Liebling MR, Hudson NP, Berner CM, Coutts S, de Haan HA. Treatment of systemic lupus erythematosus with LJP 394. The Journal of rheumatology. 2001; 28: 257-65. 
42 Alarcon-Segovia D, Tumlin JA, Furie RA, McKay JD, Cardiel MH, Strand V, Bagin RG, Linnik MD, Hepburn B. LJP 394 for the prevention of renal flare in patients with systemic lupus erythematosus: results from a randomized, double-blind, placebocontrolled study. Arthritis and rheumatism. 2003; 48: 442-54. 10.1002/art.10763.

43 Cardiel MH, Tumlin JA, Furie RA, Wallace DJ, Joh T, Linnik MD. Abetimus sodium for renal flare in systemic lupus erythematosus: results of a randomized, controlled phase III trial. Arthritis and rheumatism. 2008; 58: 2470-80. 10.1002/art.23673.

44 Horowitz DM, Furie RA. Abetimus sodium: a medication for the prevention of lupus nephritis flares. Expert opinion on pharmacotherapy. 2009; 10: 1501-7. $10.1517 / 14656560902946419$.

45 Frohlich K, Holle JU, Aries PM, Gross WL, Moosig F. Successful use of bortezomib in a patient with systemic lupus erythematosus and multiple myeloma. Annals of the rheumatic diseases. 2011; 70: 1344-5. 10.1136/ard.2010.133256.

46 Illei GG, Shirota Y, Yarboro CH, Daruwalla J, Tackey E, Takada K, Fleisher T, Balow JE, Lipsky PE. Tocilizumab in systemic lupus erythematosus: data on safety, preliminary efficacy, and impact on circulating plasma cells from an open-label phase I dosage-escalation study. Arthritis and rheumatism. 2010; 62: 542-52. 10.1002/art.27221.

47 Szepietowski JC, Nilganuwong S, Wozniacka A, Kuhn A, Nyberg F, van Vollenhoven RF, Bengtsson AA, Reich A, de Vries DE, van Hartingsveldt B, Robinson DW, Jr., Gordon R, Hsu B. Phase I, randomized, double-blind, placebo-controlled, multiple intravenous, dose-ascending study of sirukumab in cutaneous or systemic lupus erythematosus. Arthritis and rheumatism. 2013; 65: 2661-71. 10.1002/art.38091.

48 Sthoeger Z, Sharabi A, Mozes E. Novel approaches to the development of targeted therapeutic agents for systemic lupus erythematosus. Journal of autoimmunity. 2014; 54: 60-71. 10.1016/j.jaut.2014.06.002. 
49 Petri M, Wallace DJ, Spindler A, Chindalore V, Kalunian K, Mysler E, Neuwelt CM, Robbie G, White WI, Higgs BW, Yao Y, Wang L, Ethgen D, Greth W. Sifalimumab, a human anti-interferon-alpha monoclonal antibody, in systemic lupus erythematosus: a phase I randomized, controlled, dose-escalation study. Arthritis and rheumatism. 2013; 65: 1011-21. 10.1002/art.37824.

50 AstraZeneca. AstraZeneca announces Medlmmune's mavrilimumab and sifalimumab both met primary endpoints in Phase Ilb studies. [Press release]. [Accessed on 19/09/2014]. http://wwwastrazenecacom/Media/Press-releases/Article/20140512-astrazeneca-announces-medimmunes-mavrilimumab-sifalimumab-met-primary-endpointsPhase-Ilb-studies 2014.

51 McBride JM, Jiang J, Abbas AR, Morimoto A, Li J, Maciuca R, Townsend M, Wallace DJ, Kennedy WP, Drappa J. Safety and pharmacodynamics of rontalizumab in patients with systemic lupus erythematosus: results of a phase I, placebo-controlled, double-blind, dose-escalation study. Arthritis and rheumatism. 2012; 64: 3666-76. 10.1002/art.34632.

52 Lauwerys BR, Hachulla E, Spertini F, Lazaro E, Jorgensen C, Mariette X, Haelterman E, Grouard-Vogel G, Fanget B, Dhellin O, Vandepapeliere P, Houssiau FA. Down-regulation of interferon signature in systemic lupus erythematosus patients by active immunization with interferon alpha-kinoid. Arthritis and rheumatism. 2013; 65: 447-56. 10.1002/art.37785. 
Table 1. Novel biological therapies for systemic lupus erythematosus.

Mechanism

Targeting surface molecules on B cells

Targeting B cell growth and survival factors

Toleragen molecule
Proteasome inhibition

Targeting co-stimulatory molecules

Targeting T cells

Targeting cytokines - IL 6

Targeting cytokines - type I interferons

\section{Agent}

Ocrelizumab (fully humanized anti-CD20)

Epratuzumab (fully humanized anti-CD22)

Atacicept

Blisibimod

Tabalumab

Abetimus sodium

Bortezomib

AMG 557 (against B7RP-1, an inducible co-stimulator ligand)

Edratide

Rigerimod

Laquinimod

Tocilizumab

Sirukumab

Sifalimumab

Rontalizumab 